\title{
Mitochondrial DNA phylogeography and population history of the grey wolf Canis lupus
}

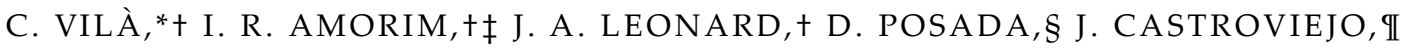 \\ F. PETRUCCI-FONSECA, $\ddagger$ K. A. CRANDALL, $\S$ H. ELLEGREN* and R. K. WAYNE† \\ *Department of Evolutionary Biology, Uppsala University, Norbyvägen 18D, S-752 36 Uppsala, Sweden, †Department of \\ Organismic Biology, Ecology and Evolution, University of California, 621 Charles E. Young Drive, Los Angeles, CA 90095-1606, \\ USA, †Departamento de Zoologia e Antropologia/Centro de Biologia Ambiental, Faculdade de Ciências da Universidade de Lisboa, \\ Ed. C2, Campo Grande 1749-016 Lisboa, Portugal, §Department of Zoology and M. L. Bean Museum, Brigham Young University, \\ Provo, UT 84602, USA, IEstación Biológica de Doñana, C.S.I.C., Apdo. 1056, 41080 Sevilla, Spain
}

\begin{abstract}
The grey wolf (Canis lupus) and coyote (C. latrans) are highly mobile carnivores that disperse over great distances in search of territories and mates. Previous genetic studies have shown little geographical structure in either species. However, population genetic structure is also influenced by past isolation events and population fluctuations during glacial periods. In this study, control region sequence data from a worldwide sample of grey wolves and a more limited sample of coyotes were analysed. The results suggest that fluctuating population sizes during the late Pleistocene have left a genetic signature on levels of variation in both species. Genealogical measures of nucleotide diversity suggest that historical population sizes were much larger in both species and grey wolves were more numerous than coyotes. Currently, about 300000 wolves and 7 million coyotes exist. In grey wolves, genetic diversity is greater than that predicted from census population size, reflecting recent historical population declines. By contrast, nucleotide diversity in coyotes is smaller than that predicted by census population size, reflecting a recent population expansion following the extirpation of wolves from much of North America. Both species show little partitioning of haplotypes on continental or regional scales. However, a statistical parsimony analysis indicates local genetic structure that suggests recent restricted gene flow.
\end{abstract}

Keywords: census, coyote, demography, mtDNA, nucleotide diversity, population structure

\section{Introduction}

The immediate ancestors of the grey wolf (Canis lupus) and coyote (C. latrans) were the late Pleistocene Eurasian species C. etruscus and the North American early Pleistocene form C. lepophagus, respectively (Nowak 1979). Grey wolves were once widely distributed throughout Europe, Asia and North America, and occupied a wide variety of habitats including the dry Arabian desert, the xeric Mediterranean shrublands, the coniferous forests of Siberia and the frozen tundra on Ellesmere island (Mech 1970). However, over the last few centuries the wolf has

Correspondence: C. Vilà. Fax: + 46-18-4716484; E-mail: Carles.Vila@evolution.uu.se been extirpated from most of its former range (Young \& Goldman 1944). The surviving populations are often geographically and genetically isolated from each other (Ginsberg \& Macdonald 1990; Wayne et al. 1992).

The historical distribution of the coyote was restricted to the plains and deserts of central North America (Gier 1975; Bekoff \& Wells 1986). With the disappearance of wolves and the modification of landscapes that followed the westward expansion of pioneers, the geographical range of coyotes expanded to include all the USA and most of south and northwest Canada (Macdonald 1984). These recent demographic events have left their signature on the genetic structure of both species. Coyote mitochondrial DNA (mtDNA) haplotypes are not geographically structured and coyotes interbreed with wolves in 
places where the wolf population has dramatically decreased (Lehman \& Wayne 1991; Wayne \& Jenks 1991; Roy et al. 1994). North American wolves have a rather continuous distribution throughout Canada and Alaska, and, as with the coyotes, no well-defined phylogeographical structure is observed (Roy et al. 1994). However, in Europe and perhaps in Asia, wolf populations are genetically isolated and have reduced genetic variability, possibly as a result of recent population bottlenecks (Wayne et al. 1992; Randi et al. 1995; Ellegren et al. 1996).

In this study, the genetic variability and relationships of grey wolves throughout the world based on control region sequences were assessed. The genetic variability of wolves was compared with coyotes, which provided insights into the origin of both species and their Pleistocene diversification. Finally, genetic information on wolves was integrated to identify populations with low levels of genetic variation and to define evolutionary and management units for conservation (Moritz 1994).

\section{Materials and methods}

\section{Samples}

Control region sequences of 167 and 59 grey wolves were obtained from a previous study on the origin of genetic variability in dogs (Vilà et al. 1997) and from population studies of grey wolves (Ellegren et al. 1996; Taberlet et al. 1996; Tsuda et al. 1997; Pilgrim et al. 1998), respectively. New sequences were obtained from blood and tissue samples of 33 additional wild and captive wolves (Table 1). Wolves from areas where wolf-coyote hybridization is known to occur (Lehman et al. 1991) and which were found to carry coyote-like mtDNA sequences, have been excluded from the analysis. From the study of Ellegren et al. (1996), only wild Scandinavian wolves and wild-caught founders of the captive population were considered. In total, mtDNA sequences from 259 wolves from 30 localities worldwide were analysed (Table 1). The frequency of close relatives in the sample is probably low because samples were collected opportunistically over many years and over a wide area at each locality.

Tissue samples of 12 coyotes from different localities in North America were analysed (California, $n=4$; Florida, $n=1$; Louisiana, $n=1$; Manitoba, $n=1$; Michigan, $n=1$; Texas, $n=2$; Utah, $n=1$; and Washington, $n=1$ ). Sequences from faeces of Mexican $(n=2)$ and Minnesotan $(n=1)$ canids and a Texan red wolf (Canis rufus) which had sequences classified with those from coyotes, were also included. Finally, published sequences from two Montanan coyotes (Pilgrim et al. 1998) were included. One Ethiopian wolf (C. simensis), one golden jackal (C. aureus) and one black-backed jackal (C. mesomelas) were sequenced to be used as outgroups in the phylogenetic analysis.

\section{DNA extraction and amplification}

DNA was isolated using slight variations on phenolchloroform extraction methods (Sambrook et al. 1989). For the coyote faeces, DNA was isolated following Höss \& Pääbo (1992). Amplification of a 350 bp fragment of the control region I (Saccone et al. 1987) was performed via the polymerase chain reaction (PCR) using universal primers Thr-L 15926 5'-CAATTCCCCGGTCTTGTAAACC-3' and DL-H 16340 5'-CCTGAAGTAGGAACCAGATG-3' (modified from Kocher et al. (1989)). Extraction and notemplate PCR controls were used in each amplification. Each PCR mixture contained approximately $100 \mathrm{ng}$ of DNA, 25 pmol of each primer and $1 \mathrm{~mm}$ dNTP in a reaction buffer of $50 \mathrm{~mm} \mathrm{KCl}, 2.5 \mathrm{~mm} \mathrm{MgCl}_{2}, 10 \mathrm{~mm}$ Tris- $\mathrm{HCl}$ ( $\mathrm{pH} 8.8$ ), and 1.5 units of Taq DNA polymerase (Promega) in a total volume of $50 \mu \mathrm{L}$. Thirty-five cycles of amplification were performed in a programmable thermal cycler (Perkin-Elmer Cetus, Model 480). Each cycle consisted of denaturation at $94{ }^{\circ} \mathrm{C}$ for $60 \mathrm{~s}$, annealing at $50{ }^{\circ} \mathrm{C}$ for $120 \mathrm{~s}$, and extension at $72{ }^{\circ} \mathrm{C}$ for $90 \mathrm{~s}$, with a final extension at $72{ }^{\circ} \mathrm{C}$ for $7 \mathrm{~min}$. The PCR products were separated in a 1$2 \%$ Nusieve (FMC Corp.) agarose gel in TAE buffer. After staining with ethidium bromide, the appropriate band was excised, the DNA extracted using the Geneclean (BIO 101) or Ultra Clean 15 (Mo Bio Labs) kits, speed-vacuum dried, and eluted in 11-13 $\mu \mathrm{L}$ double-distilled $\mathrm{H}_{2} \mathrm{O}$.

\section{DNA sequencing}

Direct sequencing of double-stranded DNA (Sanger et al. 1977) was carried out using modifications of dimethylsulphoxide (DMSO)-based protocols (Winship 1989) and the Sequenase version 2.0 kit (US Biochemicals). The sequencing reaction products were separated by electrophoresis in a $6 \%$ polyacrylamide gel for $3 \mathrm{~h}$ at $55 \mathrm{~W}$ in a Stratagene Base Ace Sequencing apparatus. Sequence autorads were scored on an IBI gel reader, and entered into the macvector computer program (IBI-Kodak). Some samples were sequenced using dye terminator cycle sequencing chemistry on an ABI 377 instrument (Perkin-Elmer).

Sequences were aligned first by eye, then by using clustal v (Higgins et al. 1992), and rechecked by eye. Although over $350 \mathrm{bp}$ of sequence information was obtained, only a fragment of 230-231 bp for the wolves and about $226 \mathrm{bp}$ for coyotes, were considered consistent with all the studies in Table 1. This reduction in sequence size does not represent a significant loss of information, as the available information shows that only two variable positions for wolves are excluded, one of them representing a change that is present in only one sequence. Finally, one area of uncertain alignment, including a 19-20 bp segment in wolves and 11-14 bp in coyotes, was also excluded from the analysis for interspecific comparisons. 
Table 1 Distribution of wolf haplotypes at each sampled location. The number of samples, different haplotypes and unique haplotypes are indicated for each column (population)

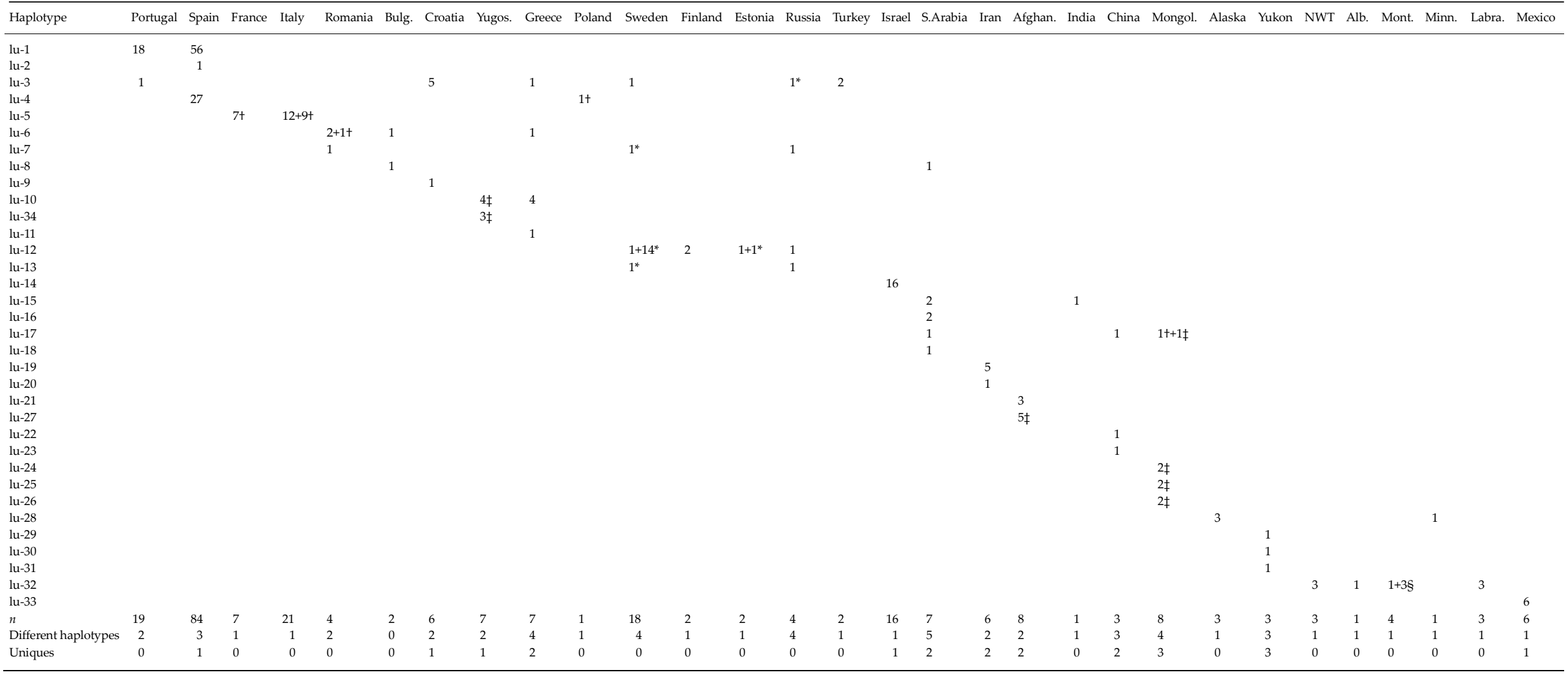

*Sequences from Ellegren et al. (1996); tsequences from Taberlet $e$ al. (1996); ; sequences from Tsuda et al. (1997); Ssequences from Pilgrim $e$ al. (1998).

Bulg., Bulgaria; Yugos., Yugoslavia; S. Arabia, Saudi Arabia; Afghan., Afghanistan; Mongol,, Mongolia; NWT, Northwest Territories (Canada); Alb., Alberta (Canada); Mont., Montana (USA); Minn., Minnesota (USA); Labra., Labrador (Canada). 


\section{Relationship of mtDNA control region sequences}

Nucleotide diversity, $\pi$ (Nei \& Li 1979), and its standard deviation (SD) for wolf and coyote haplotypes were estimated using the program dnasp (Rozas \& Rozas 1997). For mtDNA data, the parameter $\theta$ equals $N \mu$, where $N$ is the female effective population size and $\mu$ is the mutation rate per site per generation. An estimate of the effective number of females can be derived from this relationship if $\theta$ is estimated and a mutation rate is assumed. Tajima (1983) showed that $E(\theta)=\pi$, and we will denote this estimate as $o_{T}$. However, this estimator does not use genealogical information, and therefore is not efficient (Felsenstein 1992). Consequently, a maximum likelihood estimator of $\theta$ denoted $o_{F}$, that utilizes genealogical information and allows for variable population size was also used (Kuhner et al. 1995). To estimate $o_{F}$ the computer program fluctuate 1.3 was used (Kuhner et al. 1998).

To select the model of DNA substitution that best fitted the data, a hierarchical likelihood ratio test approach implemented in the program modeltest 1.03 was used (Posada \& Crandall 1998). The model selected was the Hasegawa et al. (1985) model of substitution with rate heterogeneity $(\mathrm{HKY}+\Gamma)$. Using this model, the transition/ transversion ratio (ti/tv) and gamma shape parameter $(\alpha)$ were 15.47 and 0.317 for the combined data set; 41.85 and 0.006 for coyotes; and 12.37 and $<0.001$ for wolves. The phylogenetic relationships between haplotypes were reconstructed using the neighbour-joining method (Saitou \& Nei 1987) under the HKY $+\Gamma$ model of evolution with the parameter estimates given above. Confidence in estimated relationships was determined using the bootstrap approach (Felsenstein 1985). Bootstrap values were obtained through 1000 replicates incorporating the same model as above. Bootstrap analysis and phylogeny reconstruction were performed using paup version $4.01 \mathrm{~b}$ (Swofford 1998). The rates of evolution in coyote and wolf sequences were compared using Tajima's (1993) test.

The genetic similarity between populations may be due to ongoing gene flow or reflect recent colonization (Crandall \& Templeton 1993). A statistical parsimony approach (Templeton et al. 1992) was used to construct a network to separate population history from population structure. Parsimonious $\left(P_{j} \geq 0.95\right)$ connections were statistically justified for haplotypes that differed by up to six mutational differences (Templeton et al. 1992). A matrix of absolute pairwise differences was calculated considering gaps as a fifth state (program by D. Posada, available on request). This matrix was used to construct the statistical parsimony cladogram. Haplotypes were nested to better visualize higher-order patterns of association (Templeton \& Sing 1993). Networks may more effectively portray the relationships among sequences for populations in which many sequences may be derived from the same ancestral genotype. Geographical association was tested for, treating each sample location as a categorical variable (Hudson et al. 1992). A permutational contingency analysis of the categorical variation was performed using the Roff \& Bentzen (1989) algorithm for assessing the significance of the test statistic (program by D. Posada, available on request).

Regional patterns of geographical subdivision, gene flow and effective population sizes

The average sequence divergence between wolf populations was used to construct a neighbour-joining tree. One hundred bootstrap sequence data sets were similarly analysed to study the support of the neighbour-joining tree using the software phylip 3.57c (Felsenstein 1989). This tree provided guidance in testing the significance of geographical population genetic units in an analysis of molecular variance (amova) approach (Excoffier et al. 1992). amova is a hierarchical analysis analogous to analysis of variance (anova) in which the correlations among genotype distances at various hierarchical levels are used as F-statistic analogues, designated as $\Phi$-statistics. $\Phi_{\text {ST }}$ is the correlation of random genotypes within a population relative to that from the whole species and is analogous to $F_{S T}$ of Wright (1951), $\Phi_{\mathrm{CT}}$ is the correlation of random genotypes within a group of populations relative to that drawn from the entire species and measures the proportion of genetic variation among groupings of populations, and lastly $\Phi_{\mathrm{SC}}$ is the correlation of random genotypes within populations relative to that within a regional grouping of populations and measures the proportion of variation among populations within a region. The significance of these $F$-statistic analogues is evaluated by random permutations of sequences among populations. We experimented with various groupings of populations suggested by the analysis of DNA sequence and population trees (see above) and those suggested by taxonomy and geographical isolation. The groupings that maximized values of $\Phi_{\mathrm{CT}}$ and were significantly different from random distributions of individuals were assumed to be the most probable geographical subdivisions.

Gene flow within and among regions was expressed as the number of female migrants per generation, $N_{m^{\prime}}$ where $N$ is the female effective population size and $m$ is the female migration rate. $N_{m}$ was approximated by the expression $F_{\mathrm{ST}}=1 /\left(1+2 N_{m}\right)$ (Wright 1951; Slatkin 1987, 1993; Baker et al. 1994). Pairwise estimates of $\Phi_{\mathrm{ST}}$ were used as surrogates for $F_{\mathrm{ST}}$ among regional groupings of populations and migration rates were calculated (Stanley et al. 1996). amova, pairwise $\Phi_{\mathrm{ST}}$ and $N_{m}$ values, as well as the nucleotide diversity for each population, were calculated using arlequin 1.1 (Schneider et al. 1997). Maximum likelihood estimates of $N_{m}$ were also obtained 
using the program migrate 0.6 (Beerli \& Felsenstein submitted). This method uses a coalescent theory approach to estimate past migration rates between populations assuming a migration matrix model with asymmetric migration rates and different subpopulation sizes. The significance of the differences in nucleotide diversity between populations was assessed with a Kruskal-Wallis test (Sokal \& Rohlf 1981).

Following Slatkin (1993), differentiation by distance was assessed by plotting pairwise $\log \left(N_{m}\right)$ values agains log geographical distance. The significance of the associ ation was determined by applying Mantel's permutatior test (Mantel 1967). A significant association between $N_{n}$ and distance indicates genetic structuring in populations and that dispersal of individuals is limited (Slatkin 1993).

\section{Results}

\section{Sequence divergence in coyotes and wolves}

Haplotype diversity was much greater in coyotes than in wolves. Thirty-four different mtDNA haplotypes were found in 259 wolves and 15 in 17 coyotes. Wolf sequences differed by one to 12 substitutions and had indels at two positions. Coyote sequences differed by one to 14 substitutions and had indels in seven positions. The nucleotide diversity $\left(\pi\right.$ or $o_{T}$ ) among haplotypes in wolves, $0.026(\mathrm{SD}=0.014)$, was significantly less than the value of $0.046(\mathrm{SD}=0.025)$ in coyotes (Student's $t$-test, $P<0.05$ ). By contrast, the maximum likelihood estimates of theta $\left(o_{F}\right)$ were considerably larger in both species, and the value of $0.744(\mathrm{SD}=0.133)$ in wolves was significantly larger than the value of $0.373(\mathrm{SD}=0.103)$ in coyotes (Student's $t$-test, $P<0.05$ ).

The average within-species sequence divergence, corrected for multiple hits using the HKY mutation model $(\alpha=0.317)$, and with a transition/transversion ratio of 15.47 , was $2.9 \%$ (standard error $(\mathrm{SE})=0.05$, range: $0-7.4 \%$ ) and $4.2 \%$ (SE $=0.20$, range: $0.5-8.3 \%$ ) for wolves and coyotes, respectively. These divergence estimates were significantly different (Student's $t$-test, $P<0.001$ ). The average sequence divergence between wolves and coyotes was $13.1 \%$ (SE $=0.09$, range: $8.0-19.2 \%$ ).

The larger divergence among coyote sequences relative to that among grey wolves was also indicated by the longer terminal branch lengths of coyotes in a neighbourjoining tree (Fig. 1). In pairwise comparisons of wolf and coyote branch lengths using three outgroup species (Ethiopian wolf, golden jackal and black-backed jackal), we failed to find any evidence for substitution rate variation between species (Tajima (1993) test, $P>0.05)$. Consequently, these results suggest that coyote mitochondrial control region sequences diverged at a more ancient time than did sequences in grey wolves.
The distribution of the number of pairwise substitutions between haplotypes also differed between the two species (Fig. 2). Wolves had a strongly unimodal distribution with a modal value of five (mean: $5.27, \mathrm{SE}=0.09$ ). By contrast, in coyotes, a distinct mode was not apparent, the distribution was ragged and values between four and 11 substitutions were equally common. The mean number of pairwise differences in coyotes, $7.35(\mathrm{SE}=0.31)$, was significantly higher than that for wolves (Mann-Whitney $U$-test, $P<0.001)$. Although the mismatch distribution in wolves did not show significant kurtosis $\left(g_{2}=-0.196\right.$. Student's $t$-test, $P>0.05$; Sokal \& Rohlf 1981), the distribution was significantly platykurtic for coyotes, it was more clumped, broader and modal values were not well defined $\left(g_{2}=-0.930\right.$; Student's $t$-test, $\left.P<0.05\right)$. The distribution of the pairwise distances between wolves and coyotes was clearly unimodal, with the modal values of 19 and 20 substitutions (mean: 18.79, SE = 0.10; Fig. 2c).

\section{Phylogeography}

Control region sequences of wolves were often restricted to a single locality or shared only between neighbouring localities (Table 1, e.g. lu-1, lu-2, lu-5, lu-6). However, a few haplotypes had a much wider distribution. The extreme example is lu-3, which was found in wolves from Portugal, Croatia, Greece, Sweden, European Russia and Turkey. Haplotype lu-8 was found in Bulgaria and Saudi Arabia; and lu-32 was found in the Northwestern Territories, Alberta, Montana and Labrador. In coyotes, only three haplotypes were found in more than one individual, and in each case, individuals with identical haplotypes were from the same locality.

Only 16 parsimony-informative sites were found for wolves and for coyotes. The small number of parsimonyinformative sites, together with the high number of haplotypes (34 for wolves and 15 for coyotes) prevented full resolution of phylogenetic relationships using maximum likelihood and parsimony methods. The statistical parsimony technique, which is more powerful when the sequences differ in a few sites (Crandall \& Templeton 1996), was used to understand relationships among genotypes and their correspondence with geographical distribution (Fig. 3; Crandall \& Templeton 1993).

In general, Old World haplotypes from geographically neighbouring areas were linked by one or two substitutions in the statistical parsimony network (e.g. lu-1 and lu-2 from the Iberian Peninsula; lu-5, lu-6 and lu-34 from France, Italy, Romania, Bulgaria, Yugoslavia and Greece) (Fig. 3). However, overall, there was no clear geographical pattern in the distribution of haplotypes. Sequences from North American wolves clustered in three groups. One contained the three haplotypes found in Yukon, which were characterized by a unique insertion. Another 


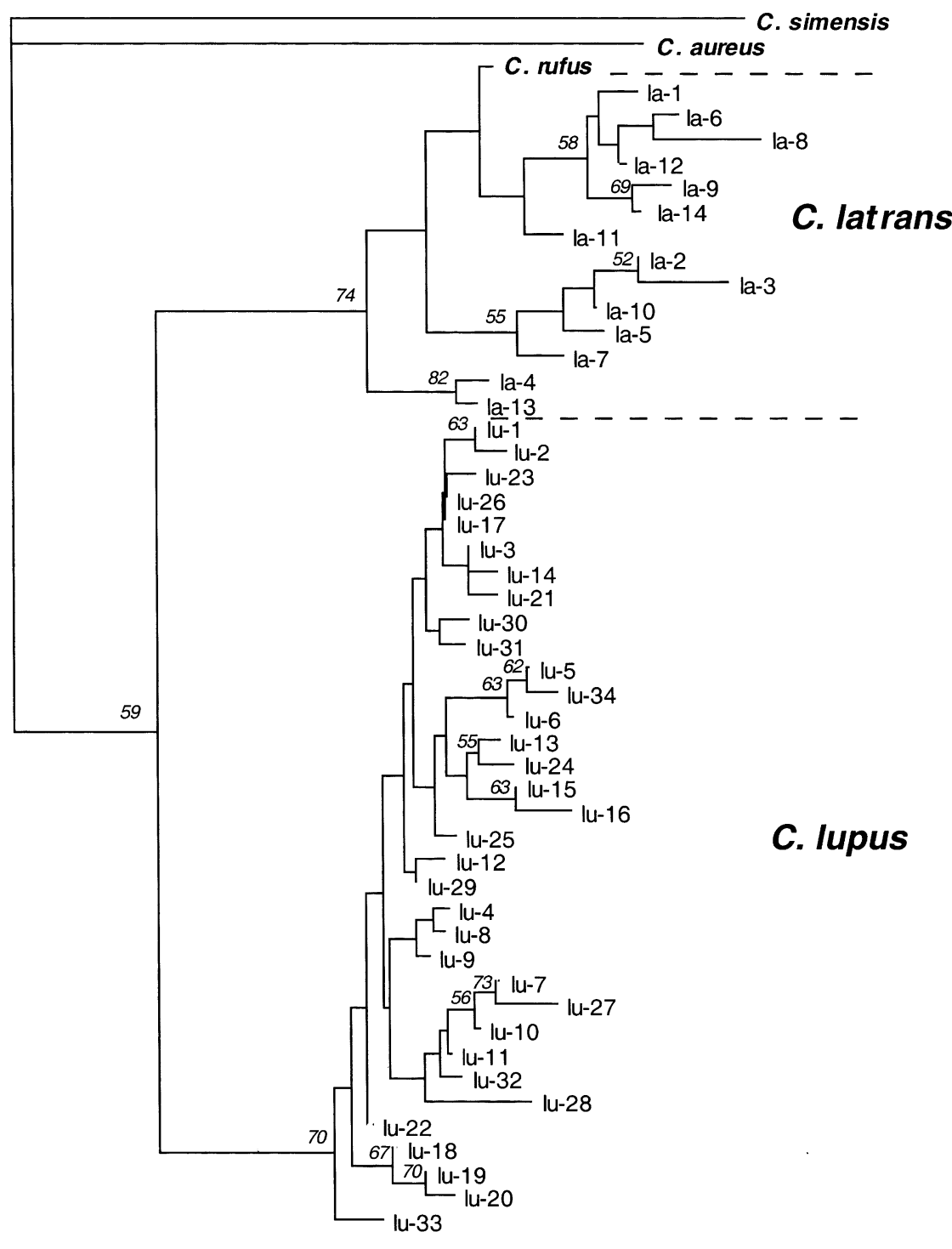

Fig. 1 Neighbour-joining tree based on the HKY model of sequence divergence with a gamma shape parameter of $\alpha=0.317$ and a transition/transversion ratio of 15.47. Bootstrap support is indicated at nodes if found in more than $50 \%$ of 1000 bootstrap trees.

group contained the most widely distributed haplotypes, lu-28 and lu-32. Finally, the haplotype found only in Mexican wolves (lu-33) defined a distinct lineage, minimally five substitutions and one indel different from other North American grey wolf sequences. North American populations appear to have greater continuity and less subdivision than their Old World counterparts. The same sequence (lu-32) was found over a wide geographical range, and lu-28 was found both in Alaska and Minnesota. However, the sequences from Yukon formed a distinct group (lu-29, lu-30, lu-31).

Using the algorithm of Templeton et al. (1992), all control region haplotypes could be connected in a single network (Fig. 3). When changes were mapped in the cladogram the amount of parallelisms and reversals was high. At the 25 variable sites, 73 mutational steps were observed in the cladogram, resulting in an average of nearly three changes per site. This high amount of homoplasy was also indicated by the extremely low value of the gamma shape parameter $(\alpha<0.001$, see Materials and methods) which indicated a skewed distribution with the majority of changes occurring at a few sites. As most of the changes were transitions ( $\mathrm{ti} / \mathrm{tv}=12.37$ ), multiple hits in a single position will very often not be noticed as they would represent reversal to the ancestral condition. Consequently, the cladogram was complex and had loops connecting three or more haplotypes. Because this complexity makes the nesting procedure ambiguous, we did not perform a nested analysis (Templeton \& Sing 1993) and only indicated a subset of the possible nested groups.

Some haplotypes from geographically neighbouring areas formed part of one-step clades (e.g. lu-1 and lu-2 from the Iberian Peninsula; lu-19 and lu-20 from Iran; lu-5 and lu-34 from France, Italy and Yugoslavia), but other 

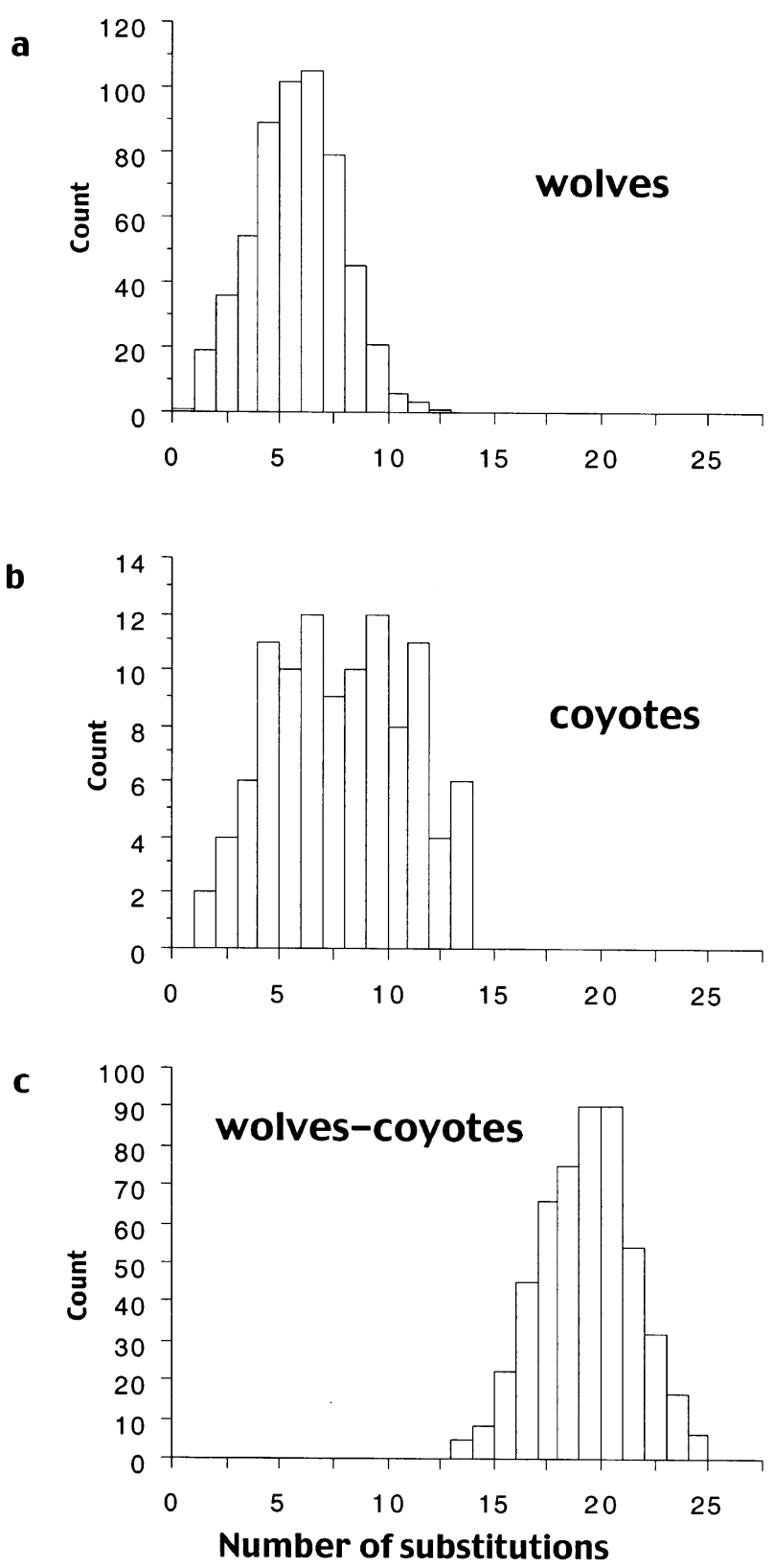

Fig. 2 Distribution of pairwise distances (measured as number of substitutions) (a) between wolf haplotypes, (b) between coyote haplotypes, (c) between wolf and coyote haplotypes. A region of difficult alignment between species has been excluded in all comparisons (see Materials and methods).

one-step clades included haplotypes from very distant localities (e.g. lu-12 and lu-29, from Northern Europe and Yukon). A permutation categorical contingency analysis of the whole cladogram rejected the null hypothesis of no association with geographical location $(P<0.001)$. Therefore, the distribution of lineages was not randomized with respect to geography. However, overall, there was no clear geographical pattern in the distribution of haplo- types. Even at the continental level, haplotypes found in Europe, Asia and America were not grouped in exclusive clusters. Most of the Asian haplotypes appeared as interior nodes (Fig. 3) whereas the European and American haplotypes appeared in terminal positions. Haplotypes located at the tips of the cladogram tended to have restricted geographical distributions whereas ubiquitous, and presumably ancestral haplotypes, were on interior nodes (e.g. lu-3, lu-7, lu-8, lu-12, lu-17, lu-32).

\section{Population diversity and relationships}

Nucleotide diversity differed significantly among grey wolf populations (Tables 1 and 2; Kruskal-Wallis test, $H=456.90$, d.f. $=13, P<0.001)$. This result does not reflect sample size differences alone because nucleotide diversity did not increase with sample size as expected. Wellsampled European populations had lower nucleotide diversity and fewer divergent haplotypes (Portugal, Spain, Italy, Sweden or Israel) than populations in which only a few wolves had been sampled (e.g. Yugoslavia, Greece, Saudi Arabia, Afghanistan or Mongolia).

The general structure of the neighbour-joining population tree does not support higher-order groupings according to geographical proximity (Fig. 4). None of the resulting nodes was supported in $50 \%$ or more of 100 bootstrap trees. Some neighbouring populations were located on the same branches (e.g. Portugal and Spain; Italy, France and Romania; most North American populations; Sweden, Finland and Estonia; Croatia, Turkey and Israel), but regional or continental groups were not suggested by the structure of the tree. To determine if populations that were poorly sampled contributed to the lack of phylogeographical structure, we made trees with a subset of well-sampled populations. These trees did not differ in general structure from that presented in Fig. 4.

For the amova analysis, populations were grouped in different hierarchical arrangements to uncover groupings with the maximum value of $\Phi_{\mathrm{CT}}$. A wide array of groupings were tested (Table 3). Populations that were thought to be part of the same breeding population and were not significantly differentiated were always considered as a single interbreeding population (i.e. Portugal and Spain, France and Italy). The highest $\Phi_{\mathrm{CT}}$ values were obtained when most Asian populations were considered independent and most populations from Canada and the USA were classified in the same group. European populations formed several groups. The maximum $\Phi_{\mathrm{CT}}$ was 0.62 and $\Phi_{\text {ST }}$ was 0.69 (Table 3). The $\Phi_{\text {CT }}$ values obtained by grouping localities by continents or as North America and Eurasia showed that these groupings were clearly worse; variance among groups represented only $19 \%$ and $8 \%$, respectively.

The number of migrants per generation $\left(N_{m}\right)$ estimated using $\Phi_{\mathrm{ST}}$ values from the pairwise comparison of 


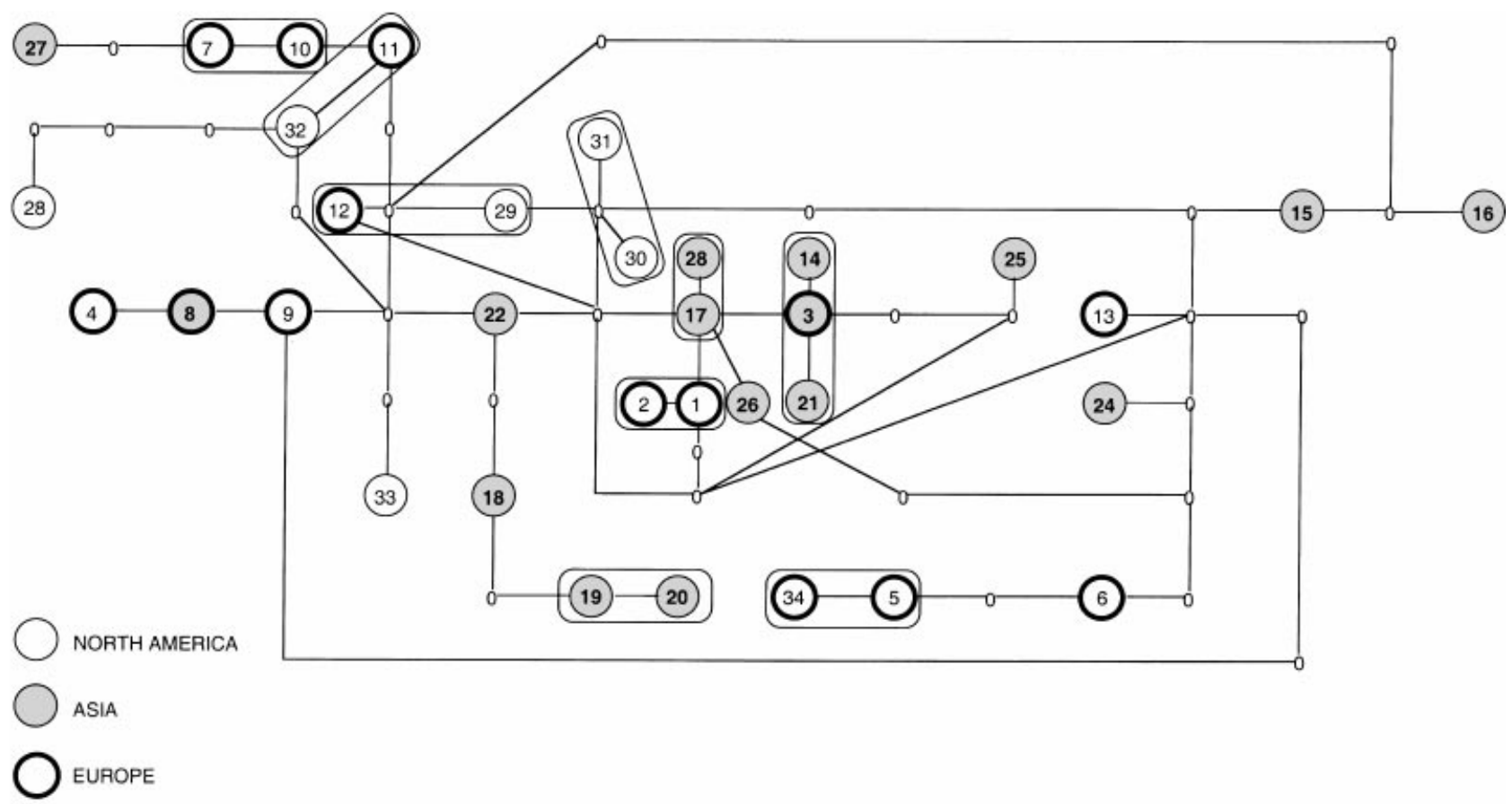

Fig. 3 Statistical parsimony cladogram (Templeton et al. 1992) of wolf haplotypes based on the number of substitutions and presence of indels between sequences. The numbers indicate the haplotypes as in Table 1 . The continent where each haplotype was found is indicated. Only one-step clades are shown. Nesting at higher levels would make the graph unreadable.

Table 2 Nucleotide diversity ( \pm standard deviation (SD)) for populations with five or more individuals (see Table 1)

\begin{tabular}{ll}
\hline & Nucleotide diversity $( \pm \mathrm{SD})$ \\
\hline Portugal & $0.000907(0.001286)$ \\
Spain & $0.003806(0.002983)$ \\
France & 0 \\
Italy & 0 \\
Croatia & $0.007184(0.005626)$ \\
Yugoslavia & $0.027094(0.016765)$ \\
Greece & $0.016010(0.010521)$ \\
Sweden & $0.006423(0.004544)$ \\
Israel & 0 \\
Saudi Arabia & $0.020115(0.012839)$ \\
Iran & $0.001456(0.001916)$ \\
Afghanistan & $0.013915(0.009135)$ \\
Mongolia & $0.014778(0.009607)$ \\
Mexico & 0 \\
\hline
\end{tabular}

populations suggested in the amova analysis, did not show any significant relationship with distance (Fig. 5, Mantel's permutation test $P>0.05)$. For example, the number of migrants between the Iberian Peninsula (Spain + Portugal) and Italy plus France was 0.11 whereas it was 1.70 between the Iberian Peninsula and China. Similarly, the number of migrants between the Yukon and Greece +
Turkey was 4.00 whereas it was 0.09 between Yukon and Alaska. As most of these populations are currently isolated from each other, $N_{m}$ values reflect past migration and methods using coalescence may be more appropriate. Maximum likelihood estimates of past migration per generation obtained using the program migrate provided very similar results. We attributed these inconsistent values to small sample size, a high level of homoplasy and violations of the island model of migration (Whitlock \& MrCanlev 1999).

\section{Discussion}

\section{Divergence of grey wolves and coyotes and Pleistocene popuıиıьоп сусьеs}

The first grey wolves appeared in the Old World about 700000 years ago (Kurtén 1968), and coyotes appeared in North America about 1 million years ago (Kurtén \& Anderson 1980). We will consider, conservatively, that the minimum date for divergence of both lineages is 1 million years (see also Nowak (1979)). The sequence divergence between coyotes and grey wolves can be corrected for ancestral within-species polymorphism using the expression $p \mathrm{wc}($ net $)=p \mathrm{wc}-(p \mathrm{w}+p \mathrm{c}) / 2$, where $p \mathrm{wc}$ is the sequence divergence (based on the HKY $+\Gamma$ distance) between coyotes and wolves, and $p_{\mathrm{w}}$ and $p_{\mathrm{c}}$ the mean 


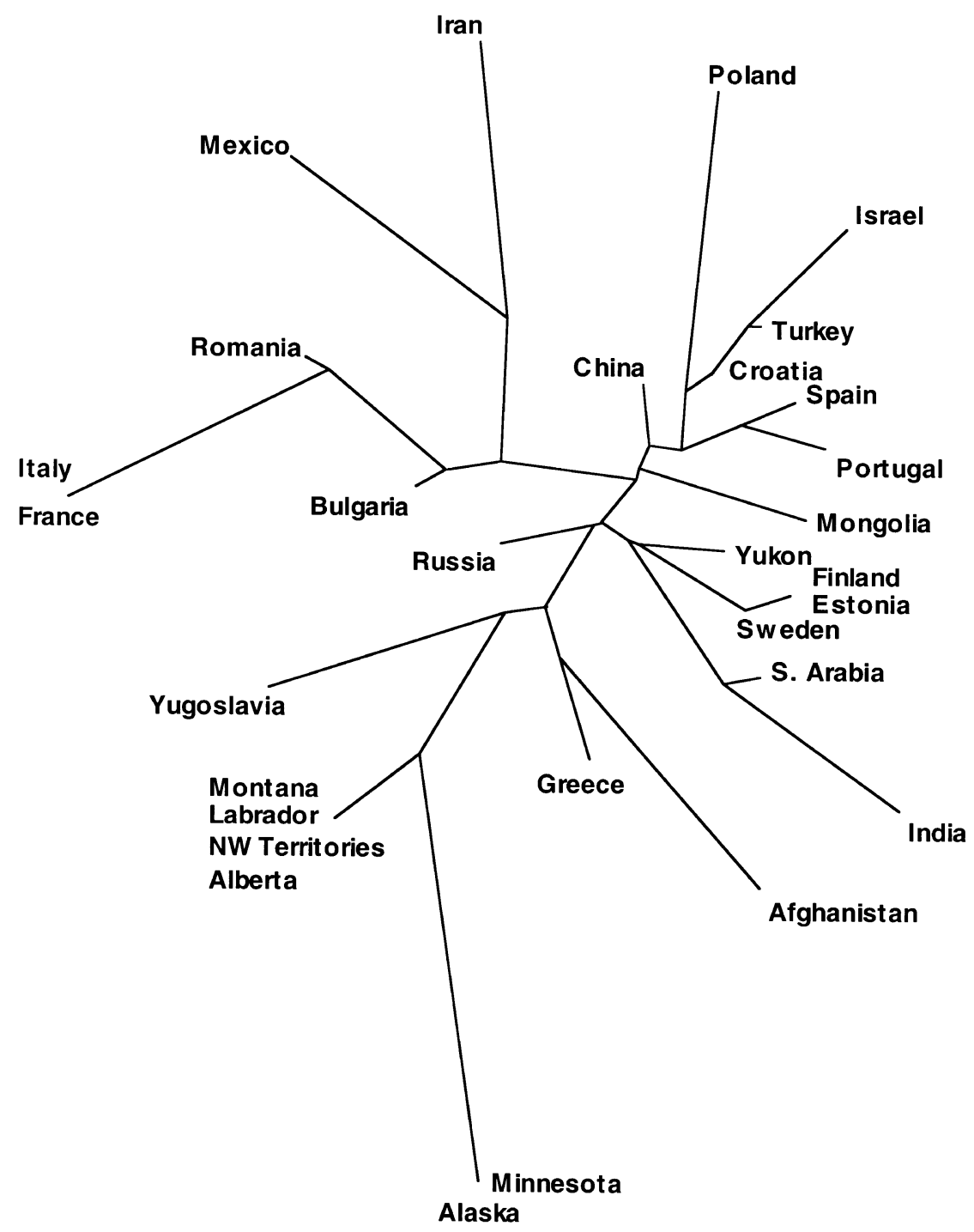

Fig. 4 Neighbour-joining tree of the populations based on the estimated number of net nucleotide substitutions between each pair of populations (Nei 1987). All nodes were supported in less than $50 \%$ of 100 bootstrap trees.

Table 3 Some examples of analysis of molecular variance (amova). Fixation indices are indicated, as well as the percentage of the total variance that is explained by the grouping and its significance. For population names see Table 1

\begin{tabular}{|c|c|c|c|c|c|}
\hline Groups & $\Phi_{\mathrm{SC}}$ & $\Phi_{\mathrm{ST}}$ & $\Phi_{\mathrm{CT}}$ & $\%$ among groups & $P$ \\
\hline \multicolumn{6}{|l|}{ [Spain, Portugal] [France, Italy] [Romania, Bulg.] [Croatia] [Yugos.] } \\
\hline \multicolumn{6}{|l|}{ [Poland, Estonia, Sweden, Finland, W Russia] [Greece, Turkey] } \\
\hline \multicolumn{6}{|l|}{ [Israel] [Iran] [Afghan.] [India] [S Arabia] [China] [Mongol.] } \\
\hline [Alaska] [Yukon] [NWT, Alb., Mont., Minn., Labra.] [Mexico] & 0.185 & 0.689 & 0.619 & 61.89 & $<0.01$ \\
\hline [Eurasia] [America] & 0.661 & 0.724 & 0.186 & 18.55 & $<0.05$ \\
\hline [Eurasia] [USA, Canada] [Mexico] & 0.650 & 0.749 & 0.284 & 28.38 & $<0.01$ \\
\hline [Europe] [Asia] [USA, Canada] [Mexico] & 0.660 & 0.689 & 0.086 & 8.55 & 0.09 \\
\hline \multicolumn{6}{|l|}{ [Spain, Portugal] [France, Italy] [Romania, Bulg.] [Croatia] } \\
\hline \multicolumn{6}{|l|}{ [Yugos.] [Greece, Turkey] [Poland, Estonia, Sweden, Finland, } \\
\hline \multicolumn{6}{|c|}{ W Russia] [Israel] [S Arabia] [Iran] [Afghan.] [India, China] [Mongol.] } \\
\hline [Alaska] [Yukon, NWT, Alb., Mont., Minn., Labra.] [Mexico] & 0.271 & 0.689 & 0.573 & 57.27 & $<0.01$ \\
\hline \multicolumn{6}{|l|}{ [Spain, Portugal] [France, Italy] [Romania, Bulg., Croatia, Yugos.] } \\
\hline \multicolumn{6}{|l|}{ [Greece, Turkey] [Poland, Estonia] [Sweden, Finland] [Israel] } \\
\hline \multicolumn{6}{|l|}{ [W Russia] [S Arabia] [Iran] [Afghan.] [India, China] [Mongol.] } \\
\hline [Alaska] [Yukon, NWT, Alb., Mont., Minn., Labra.] [Mexico] & 0.344 & 0.687 & 0.523 & 52.34 & $<0.01$ \\
\hline
\end{tabular}




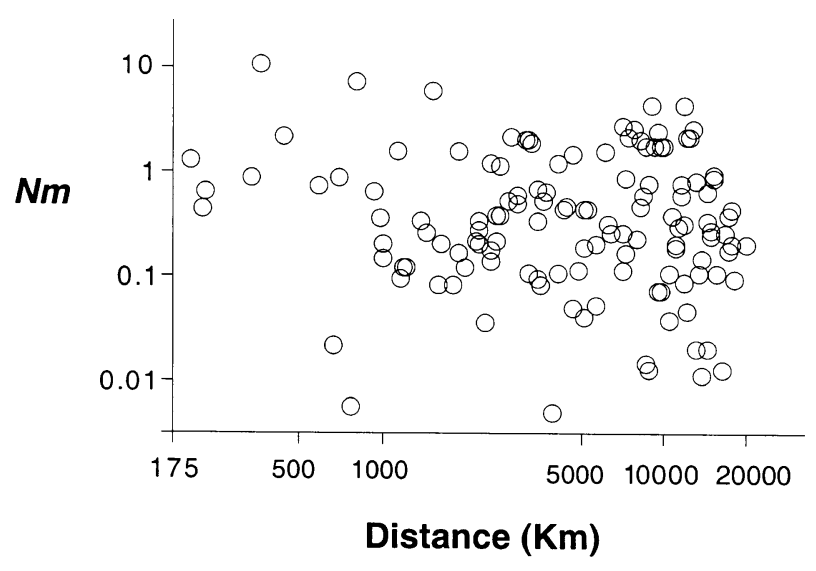

Fig. 5 Plot of the number of migrants per generation $\left(N_{m}\right)$, estimated from $\Phi_{\mathrm{ST}^{-}}$-statistics, and the geographical distance between groups defined in the amova analysis (see text). Some values of $N_{m}$ approach infinity and are not included.

sequence divergence within wolves and within coyotes, respectively (Nei 1987; Avise \& Walker 1998). The corrected sequence divergence between wolves and coyotes is $9.6 \%$. Consequently, given a divergence rate of about $10 \%$ per million years and a mean sequence divergence in grey wolves of $2.9 \%$, a coalescence of wolf haplotypes of about 290000 years ago is implied. Similarly, the mean sequence divergence in coyotes of $4.2 \%$ implies coalescence about 420000 years ago. Restriction site analysis of the whole mitochondrial genome found a similar value of $200000-400000$ years ago as the coalescence time for grey wolves (Lehman et al. 1991; Wayne et al. 1992). However, the restriction site estimate of coalescence for coyotes is about 1 million years ago, as old as the divergence between wolves and coyotes (Lehman et al. 1991). Our results suggest that the coalescence is recent for both species.

This coalescence of wolf and coyote sequences is more recent than predicted from the current population size of both species. At equilibrium between drift and mutation, and assuming a low variance in family size, the expected coalescence time in generations is two times the effective number of females (Hartl \& Clark 1989). For wolves and coyotes, the current census population size worldwide is of the order of hundreds of thousands and millions, respectively (Lehman et al. 1991). These numbers would predict a very old coalescence. The observed recent coalescence may be due to the effect of population fluctuations during Pleistocene glacial cycles on the harmonic mean of the effective population size. Historical fluctuations in population size cause the harmonic mean of the effective population size to be much smaller than the average census population size (Avise et al. 1984) and results in a more recent coalescence than predicted from census population size alone. Historical fluctuations in population size were probably common for grey wolves and coyotes, as the Ice Ages must have imposed sharp reductions in the geographical range of both species. Population size reduction during glacial maxima was probably followed by expansion during interglacial times. Such serial cycles of population expansion and contraction throughout the Pleistocene would have dramatically decreased genetic variability below that predicted from interglacial population sizes (for example, in cheetahs, see Menotti-Raymond \& O'Brien (1993)).

\section{Recent demographic declines}

Comparison of the $o_{T}$ and $o_{F}$ estimates provides insights into recent population history. While $o_{T}$ reflects current diversity and demography, $o_{F}$ uses genealogical information and thus reflects historical levels of variability (Kuhner et al. 1995). For both wolves and coyotes, $o_{F}(0.744$ and 0.373 , respectively) is much larger than $o_{T}$ (0.026 and 0.046 , respectively). This indicates that both species have been much more diverse in the recent past and that wolves were more diverse historically than coyotes (see below).

To estimate historical population sizes in wolves, we assume a substitution rate of about $5 \times 10^{-8}$ per nucleotide site per year for the control region (half of the sequence divergence between coyote and grey wolf, see above). Given a mean generation time of 3 years (Mech \& Seal 1987), and a value of $o_{F}$ equal to 0.744 in wolves, a historical effective population size of about 5 million breeding females is implied. Similarly, assuming a mean generation time of 2 years for coyotes (Bekoff \& Wells 1986; Nowak 1991), a value of $o_{F}$ equal to 0.373 implies an effective number of breeding females of 3.7 million. We suggest that the dramatic difference in the historical relative abundance of the two species reflects late Pleistocene changes in habitat continuity and area occupied by grey wolves. In the late Pleistocene wolves had a Holarctic distribution whereas the coyote was restricted to the central plains of North America (Mech 1970; Gier 1975; Bekoff \& Wells 1986; Ginsberg \& Macdonald 1990). Wolves are more dependent on forest habitats in many parts of their distribution (Mech 1970; Carbyn 1987; Voigt \& Berg 1987) and during glacial times these habitats were severely fragmented and reduced in area (Hewitt 1996; Taberlet et al. 1998). In contrast, the plains and deserts of central North America were less sensitive to the fragmentation induced by Pleistocene climatic changes. Therefore, the genetic variability of coyotes may have been better preserved than that of wolves although their geographical distribution was less extensive. The distribution of pairwise differences (Fig. 4) supports this interpretation as wolves seem to have had a sharper population expansion than coyotes (Rogers \& Harpending 1992; Rogers 1995).

The very recent decrease in genetic diversity suggested 
by the comparison of $o_{T}$ and $o_{F}$ in coyotes and grey wolves may have different origins. In wolves, a substantial decrease in geographical range and population size has occurred during the last few centuries (Mech 1970; Carbyn 1987; Ginsberg \& Macdonald 1990). Seton (1925) estimated that the prehistoric wolf population in North America was about 2 million individuals whereas the current population may be less than 60000 individuals (Carbyn 1987). In contrast, coyotes have increased their geographical range several-fold in the last 100 years and they are now present throughout North America (Nowak 1979; Voigt \& Berg 1987). However, this range expansion was too recent to have significantly increased the genetic variability of control region sequences. Rather, current levels of genetic variation may reflect a decrease in coyote numbers since the last glacial maximum, about 18000 years ago, as grey wolves increased their distribution into postglacial forests (see Nowak (1979)). Here, as in Yellowstone National Park and elsewhere, grey wolves actively limit coyote numbers (Mech 1970; Robbins 1997).

The current population size of wolves and coyotes as indicated by $o_{T}$ differs from that suggested by census estimates. The effective population size for females based on $o_{T}$ is about 173000 and 460000 for wolves and coyotes, respectively. Assuming that $60 \%$ of adult female wolves breed, that the sex ratio is one and that about $50 \%$ of the population are adults (Mech 1970; Packard et al. 1983; in Wayne et al. 1992), the current census population size would be approximately 1153000 wolves. This number is much greater than the estimated worldwide wolf population size of less than 300000 (Ginsberg \& Macdonald 1990). The difference between the genetic and the census estimates probably reflects the recency of the population declines that is not yet well reflected in the loss of genetic variability worldwide (e.g. González et al. 1996). For coyotes, the total population size would be about 2.2 million assuming that $70 \%$ of adult female coyotes breed, that the sex ratio is one and that adults constitute $60 \%$ of the population (Connolly \& Longhurst 1975; Lehman \& Wayne 1991). This value is less than the estimate of 7 million individuals (1.75 million breeding females) based on census data (Lehman \& Wayne 1991). As above, the higher census number in coyotes may be due to a population expansion too recent to have been recorded in the diversity of control region sequences.

\section{The phylogeography and population structure of grey wolves}

The statistical parsimony and population trees (Figs 3 and 4), amova analysis (Table 3) and lack of differentiation by distance (Fig. 5), suggest an absence of large-scale geographical structure. A similar conclusion was reached by restriction site analysis of a smaller sample of wolves from fewer localities (Wayne et al. 1992). The multiple expansions and contractions to refugia that wolf populations have experienced during the Ice Ages, together with the changes in distribution of suitable habitats, may have contributed to the general lack of phylogeographical structure. Wolves are highly mobile predators, for which dispersal distances of several hundred kilometres are common and record movements over $1000 \mathrm{~km}$ have been recorded (Fritts 1983; Mech 1987; Mech et al. 1995). Consequently, during interglacials, wolf populations would rapidly expand into favourable habitats resulting in population admixture that would obscure past phylogeographical structure caused by Ice Age isolation. The effect of Ice Ages on the distribution of wolf haplotypes is apparent in the New World. Several episodes of migration have occurred across the Bering Land Bridge (Kurtén 1963, 1966). In North America, control region sequences of Yukon and Mexican grey wolves are divergent from those of other North American wolves (Fig. 1). The Mexican wolf sequence may be derived from an early invasion of wolves into North America (Wayne et al. 1992). Similarly, the presence of divergent sequences in Yukon may represent superimposed sequences from different migrations across the Bering Land Bridge. Because grey wolves are highly mobile, glaciers are only an ephemeral isolating barrier, and the admixture after glacial retreat would increase diversity in some populations and obscures past historical population structure.

A similar phenomenon, but over a more recent timescale, has occurred in North American coyotes. As discussed above, coyotes were previously restricted to the arid lands of the USA, and have vastly expanded their geographical range in the past 100 years to all of the continental USA and much of southern and central Canada. The genetic consequences of this expansion are apparent in a restriction fragment length polymorphism (RFLP) study of coyotes (Lehman \& Wayne 1991). Divergent genotypes were found in several populations and genetic relationships between populations did not correspond to geography. For example, Californian coyotes had three times the genetic diversity of those from Minnesota, yet both are recently colonized states. The relationships of California genotypes varied as some grouped with those from Texas, others with those from Alaska (Lehman \& Wayne 1991). A microsatellite analysis (Roy et al. 1994) has confirmed the lack of geographical associations among coyote populations. A similar rapid expansion from refugial populations during postglacial periods in wolves would have obliterated the previous geographical structure that might have existed and might account for the varying levels of genetic diversity. By contrast, population differentiation due to Ice Age isolation is still apparent in the brown bear Ursus arctos (Taberlet \& Bouvet 1994; Kohn et al. 1995; Taberlet et al. 1995; Waits et al. 1998) 
and black bear U. americanus (Wooding \& Ward 1997), two species with lower levels of mobility.

The contraction of wolf populations in historical times, due to human persecution, has led to fragmentation and isolation. The majority of extant populations, especially in Eurasia, have unique haplotypes (Table 1). The expected time to fixation of a haplotype in a population is two times the effective number of females (Hartl \& Clark 1989). Thus, given the assumptions above on the structure of wolf populations, a population of 220 individuals would be expected to be fixed for a single mitochondrial haplotype in two centuries. Some European wolf populations have reached population sizes clearly smaller than this, or have been fragmented into multiple populations of smaller size (Boitani 1982; Schröder \& Promberger 1993; Ellegren et al. 1996). Thus, in the Old World, fragmentation and drift could contribute to the lack of correspondence between gene flow and distance through the random fixation of genotypes that were previously more widespread (Fig. 5; Wayne et al. 1992).

The statistical parsimony cladogram adds important resolution to our analysis. For example, restricted gene flow among regions is strongly supported by the observations that most one-step level clades include haplotypes from the same region (Fig. 3). Additionally, increasing the nesting level increases clade distances and tip clades have a smaller geographical range than interior clades (Templeton et al. 1995; Templeton 1998). Restricted gene flow can be explained by either recent habitat fragmentation as above or historical expansion followed by isolation by distance. The former seems better supported by historical evidence although a recent expansion is suggested in wolves by the unimodal distribution of pairwise differences (Fig. 2).

\section{Units for conservation}

Nearly all well-sampled population groupings were significantly differentiated with regard to genotype frequency and sequence divergence (Table 1). If nuclear data support this result, then each population might be considered as a separate management unit (Moritz 1994). The existence of significant morphological differences between wolf populations (Vilà 1993; Nowak 1996) supports their delineation as management units. However, our analysis shows that populations often contain divergent sequences. Additionally, a hierarchical geographical structure of populations was not evident. We interpret this as due to past episodes of isolation followed by admixture. Thus, the present-day fragmentation and differentiation of grey wolf populations should be viewed as a snapshot in a dynamic historical process that includes admixture. If wolf habitats were continuously distributed as in the past, many current management units might become less differentiated and would not evolve into reciprocally monophyletic groups (evolutionarily significant units; Moritz 1994). From an evolutionary perspective, admixture was probably a common feature of the historical demography of the grey wolf, only recently interrupted by human disturbance. Thus, in general, individuals from neighbouring or closely related populations can justifiably be used as a source for re-introduction or population augmentation (e.g. for reintroductions in Yellowstone National Park, see Phillips \& Smith (1996); for New Mexico, Hedrick et al. (1997)).

Final conclusions concerning the delineation of management units and the identification of source populations for re-introduction or augmentation require the analysis of nuclear markers (García-Moreno et al. 1996; Hedrick et al. 1997) and fitness-related phenotypic differences (Hedrick 1999). For example, the size of adult wolves in Arabia is one-third that of Alaskan wolves, and pelage patterns vary greatly among localities (Young \& Goldman 1944; Vilà 1993). Similarly, in North America, analysis of nuclear loci in grey wolves found evidence for genetic differentiation among closely spaced populations not separated by geographical or habitat barriers (Roy et al. 1994; Forbes \& Boyd 1997).

\section{Acknowledgements}

We are indebted to many colleagues and organizations who kindly provided wolf and coyote tissue or DNA samples, or that helped to obtain them. Among them we can mention P. Alonso, Asociación Amigos de Doñana, L. M. Barrientos, L. Boitani, L. Carbyn, E. Geffen, G. Giannatos, Grupo Lobo-Portugal, D. Huber, Y. Jhala, N. Lehman, L. Llaneza, L. D. Mech, I. Nader, P. Paquet, E. Randi, and M. T. Theberghe. Klaus P. Koepfli and M. Kohn critically reviewed the manuscript. This research was supported in part by an NSF grant to R. K. Wayne (BSR-9020282), a postdoctoral fellowship from the Spanish Ministerio de Educación y Ciencia to C. Vilà and a PhD fellowship from Junta Nacional de Investigação Cietífica e Tecnológica/Programa PRAXIS XXI, Portugal to I. R. Amorim. H. Ellegren is sponsored by the Swedish Research Councils for Agriculture and Forestry, and for Natural Sciences, and by the Olle Engkvist, Carl Trygger, and Oscar and Lili Lamms foundations.

\section{References}

Avise JC, Neigel JE, Arnold J (1984) Demographic influences on mitochondrial DNA lineage survivorship in animal populations. Journal of Molecular Evolution, 20, 99-105.

Avise JC, Walker D (1998) Pleistocene phylogeographic effects on avian populations and the speciation process. Proceedings of the Royal Society of London Series B, 265, 457-463.

Baker CS, Slade WR, Bannister JR et al. (1994) Hierarchical structure of mitochondrial DNA gene flow among humpback whales, Megaptera novaeangliae, worldwide. Molecular Ecology, 3, 313-327.

Beerli P, Felsenstein J (1999) Maximum likelihood estimation of migration rates and population numbers of two populations using a coalescent approach. Genetics, 152, 763-773. 
Bekoff M, Wells MC (1986) Social ecology and behavior of coyotes. Advances in the Study of Behavior, 16, 251-338.

Boitani L (1982) Wolf management in intensively used areas of Italy. In: (eds Harrington FG, Paquet PC) Wolves of the World. Perspectives of Behavior, Ecology and Conservation, pp. 158-172. Noyes, Park Ridge, NJ.

Carbyn LN (1987) Gray wolf and red wolf. In: (eds Nowak M, Baker JA, Obbard ME, Malloch B) Wild Furbearer Management and Conservation in North America, pp. 358-377. Ministry of Natural Resources, Ontario.

Connolly GE, Longhurst WM (1975) The effects of control on coyote populations. Bulletin of the University of California Div. Agric. Sci., 1872, 1-37.

Crandall KA, Templeton AR (1993) Empirical tests of some predictions from coalescent theory with applications to intraspecific phylogeny reconstruction. Genetics, 134, 959-969.

Crandall KA, Templeton AR (1996) Applications of intraspecific phylogenetics. In: (eds Harvey PH, Leigh Brown AJ, Maynard Smith J, Nee S) New Uses for New Phylogenies, pp. 8199. Oxford University Press, Oxford.

Ellegren H, Savolainen P, Rosén B (1996) The genetical history of an isolated population of the endangered grey wolf Canis lupus: a study of nuclear and mitochondrial polymorphisms. Philosophical Transactions of the Royal Society of London Series B, 351, 1661-1669.

Excoffier L, Smouse PE, Quattro JM (1992) Analysis of molecular variance inferred from metric distances among DNA haplotypes: application to human mitochondrial DNA restriction data. Genetics, 131, 479-491.

Felsenstein J (1985) Confidence limits on phylogenetics, an approach using the bootstrap. Evolution, 39, 783-791.

Felsenstein J (1989) PHYLIP 3.2 Manual. University of California Herbarium, Berkeley, CA.

Felsenstein J (1992) Estimating effective population size from samples of sequences: inefficiency of pairwise and segregating sites as compared to phylogenetic estimates. Genetical Research, Cambridge, 59, 139-147.

Forbes SH, Boyd DK (1997) Genetic structure and migration in native and reintroduced Rocky Mountain wolf populations. Conservation Biology, 11, 1226-1234.

Fritts SH (1983) Record dispersal of a wolf from Minnesota. Journal of Mammalogy, 64, 166-167.

García-Moreno J, Matocq MD, Roy MS, Geffen E, Wayne RK (1996) Relationships and genetic purity of the endangered Mexican wolf based on analysis of microsatellite loci. Conservation Biology, 10, 376-389.

Gier HT (1975) Ecology and behavior of the coyotes (Canis latrans). In: (ed. Fox MW) The Wild Canids, pp. 247-262. Van Nostrand Reinhold, New York.

Ginsberg JR, Macdonald DW (1990) Foxes, Wolves, Jackals and Dogs. An Action Plan for the Conservation of Canids. International Union for Conservation of Nature and Natural Resources, Gland, Switzerland.

González S, Maldonado JE, Leonard JA et al. (1998) Conservation genetics of the endangered Pampas deer (Ozotoceros bezoarticus). Molecular Ecology, 7, 47-56.

Hartl DL, Clark AG (1989) Principles of Population Genetics. Sinauer Press, Sunderland, MA.

Hasegawa M, Kishino K, Yano T (1985) Dating the human-ape splitting by a molecular clock of mitochondrial DNA. Journal of Molecular Evolution, 22, 160-174.

Hedrick PW (1999) Perspective: highly variable loci and their interpretation in evolution and conservation. Evolution, 53, 313-318.

Hedrick PW, Miller PS, Geffen E, Wayne RK (1997) Genetic evaluation of the three captive Mexican wolf lineages. Zoo Biology, 16, 47-69.

Hewitt GM (1996) Some genetic consequences of ice ages, and their role in divergence and speciation. Biological Journal of the Linnean Society, 58, 247-276.

Higgins DG, Bleasby AJ, Fuchs R (1992) clustal v: improved software for multiple sequence alignment. Computer Applications in Biosciences, 8, 189-191.

Höss M, Pääbo S (1992) DNA extraction from Pleistocene bones by a silica-based purification method. Nucleic Acids Research, 21, 3913-3914.

Hudson RR, Boos DD, Kaplan NL (1992) A statistical test for detecting geographic subdivision. Molecular Biology and Evolution, 9, 138-151.

Kocher TD, Thomas WK, Meyer A et al. (1989) Dynamics of mitochondrial DNA evolution in animals: amplification and sequencing with conserved primers. Proceedings of the National Academy of Sciences of the USA, 86, 6196-6200.

Kohn M, Knauer F, Stoffella A, Schröder W, Pääbo S (1995) Conservation genetics of the European brown bear - a study using excremental PCR of nuclear and mitochondrial sequences. Molecular Ecology, 4, 95-103.

Kuhner MK, Yamato J, Felsenstein J (1995) Estimating effective population size and neutral mutation rate from sequence data using Metropolis-Hastings sampling. Genetics, 140, 1421-1430.

Kuhner MK, Yamato J, Felsenstein J (1998) Maximum likelihood estimation of population growth rates based on the coalescent. Genetics, 149, 429-434.

Kurtén B (1963) Notes on some Pleistocene mammal migrations from the Palaearctic to the Nearctic. Eiszeitaler und Gegenwart, 14, 96-103.

Kurtén B (1966) Pleistocene mammals and the Bering bridge. Commentationes Biologicae, 29, 1-7.

Kurtén B (1968) Pleistocene Mammals of Europe. Aldine, Chicago.

Kurtén B, Anderson E (1980) Pleistocene Mammals of North America. Columbia University Press, New York.

Lehman N, Eisenhawer A, Hansen K et al. (1991) Introgression of coyote mitochondrial DNA into sympatric North American gray wolf populations. Evolution, 45, 104-119.

Lehman N, Wayne RK (1991) Analysis of coyote mitochondrial DNA genotype frequencies: estimation of the effective number of alleles. Genetics, 128, 405-416.

Macdonald DW (1984) The Encyclopedia of Mammals. Facts on File, New York.

Mantel N (1967) The detection of disease clustering and a generalized regression approach. Cancer Research, 27, 209-220.

Mech LD (1970) The Wolf: the Ecology and Behavior of an Endangered Species. University of Minnesota Press, Minneapolis, MN.

Mech LD (1987) Age, season, distance, direction, and social aspects of wolf dispersal from a Minnesota pack. In: (eds Chepko-Sade BD, Halpin ZT) Mammalian Dispersal Patterns. The Effects of Social Structure on Population Genetics, pp. 55-74. University of Chicago Press, Chicago.

Mech LD, Fritts SH, Wagner D (1995) Minnesota wolf dispersal to Wisconsin and Michigan. American Midland Naturalist, 133, 368-370.

Mech LD, Seal US (1987) Premature reproductive activity in wild wolves. Journal of Mammalogy, 68, 871-873.

Menotti-Raymond M, O’Brien SJ (1993) Dating the genetic 
bottleneck of the African cheetah. Proceedings of the National Academy of Sciences of the USA, 90, 3172-3176.

Moritz C (1994) Defining 'evolutionary significant units' for conservation. Trends in Ecology and Evolution, 9, 373-375.

Nei M (1987) Molecular Evolutionary Genetics. Columbia University Press, New York.

Nei M, Li W-H (1979) Mathematical model for studying genetic variation in terms of restriction endonucleases. Proceedings of the National Academy of Sciences of the USA, 76, 5269-2573.

Nowak RM (1979) North American Quaternary Canis. Museum of Natural History, University of Kansas, Kansas.

Nowak RM (1991) Walker's Mammals of the World, 5th edn, Vol. II. The Johns Hopkins University Press, Baltimore, MD.

Nowak RM (1996) Another look at wolf taxonomy. In: (eds Carbyn LN, Fritts SH, Seip DR) Ecology and Behavior of Wolves in a Changing World, pp. 375-389. Canadian Circumpolar Institute, Occasional Publication no. 35, Edmonton.

Packard JM, Mech LD, Seal US (1983) Social influences on reproduction in wolves. In: (ed. Carbyn LN) Wolves in Alaska and Canada: Their Status, Biology and Management, pp. 78-85. Canadian Wildlife Service, Report no. 45, Ontario.

Phillips MK, Smith DW (1996) The Wolves of Yellowstone. Voyageur Press, Stillwater, MN.

Pilgrim KL, Boyd DK, Forbes SH (1998) Testing for wolf-coyote hybridization in the Rocky Mountains using mitochondrial DNA. Journal of Wildlife Management, 62, 683-689.

Posada D, Crandall KA (1998) modeltest: testing the model of DNA substitution. Bioinformatics, 14, 817-818.

Randi E, Francisci F, Lucchini V (1995) Mitochondrial DNA restriction-fragment-length monomorphism in the Italian wolf (Canis lupus) population. Journal of Zoological Systematics and Evolutionary Research, 33, 97-100.

Robbins J (1997) In two years, wolves reshaped Yellowstone. New York Times, 147, 30 December, B13, F1 (1).

Roff DA, Bentzen P (1989) The statistical analysis of mitochondrial DNA polymorphisms: chi-square and the problem of small samples. Molecular Biology and Evolution, 6, 539-545.

Rogers AR (1995) Genetic evidence for a Pleistocene population explosion. Evolution, 49, 608-615.

Rogers AR, Harpending H (1992) Population growth makes waves in the distribution of pairwise genetic differences. Molecular Biology and Evolution, 9, 552-569.

Roy MS, Geffen E, Smith D, Ostrander EA, Wayne RK (1994) Patterns of differentiation and hybridization in North American wolflike canids, revealed by analysis of microsatellite loci. Molecular Biology and Evolution, 11, 553-570.

Rozas J, Rozas R (1997) dnasp, version 2.0: a novel software package for extensive molecular population genetic analysis. Computer Application in Biosciences, 13, 307-311.

Saccone C, Attimonelli M, Sbisá E (1987) Structural elements highly preserved during the evolution of the D-loop-containing region in vertebrate mitochondrial DNA. Journal of Molecular Evolution, 26, 205-211.

Saitou N, Nei M (1987) The neighbor-joining method: a new method for reconstructing phylogenetic trees. Molecular Biology and Evolution, 4, 406-425.

Sambrook E, Fritsch F, Maniatis T (1989) Molecular Cloning. Cold Spring Harbor Press, Cold Spring Harbor, New York.

Sanger F, Nicklen S, Coulson AR (1977) DNA sequencing with chain-terminating inhibitors. Proceedings of the National Academy of Sciences of the USA, 74, 5463-5467.

Schneider S, Kueffer J-M, Roessli D, Excoffier L (1997) ARLEQUIN, version 1.1: a Software for Population Genetic Data Analysis. Genetics and Biometry Laboratory, University of Geneva, Geneva. Schröder W, Promberger C (1993) Wolf conservation strategy for Europe. In: (eds Promberger C, Schröder W) Wolves in Europe. Status and Perspectives, pp. 2-7. Munich Wildlife Society, Munich. Seton ET (1925) Lives of Game Animals, Vol. 1, Part 1. Charles T. Branford, Boston.

Slatkin M (1987) Gene flow and the geographic structure of natural populations. Science, 236, 787-792.

Slatkin M (1993) Isolation by distance in equilibrium and nonequilibrium populations. Evolution, 47, 264-279.

Sokal RR, Rohlf FJ (1981) Biometry, 2nd edn. W.H. Freeman, New York.

Stanley HF, Casey S, Carnahan JM et al. (1996) Worldwide patterns of mitochondrial DNA differentiation in the harbor seal (Phoca vitulina). Molecular Biology and Evolution, 13, 368-382.

Swofford DL (1998) PAUP* Phylogenetic Analysis Using Parsimony and Other Methods. Sinauer Associates, Sunderland, MA.

Taberlet P, Bouvet J (1994) Mitochondrial DNA polymorphism, phylogeography, and conservation genetics of the brown bear (Ursus arctos) in Europe. Proceedings of the Royal Society of London Series B, 255, 195-200.

Taberlet P, Fumagalli L, Wust-Saucy A-G, Cossons J-F (1998) Comparative phylogeography and postglacial colonization routes in Europe. Molecular Ecology, 7, 453-464.

Taberlet P, Gielly L, Bouvet J (1996) Etude génétique sur les loups du Mercantour. Rapport pour la Direction de la Nature et des Paysages, Ministère de l'Environnement.

Taberlet P, Swenson JE, Sandegren F, Bjärvall A (1995) Localization of a contact zone between two highly divergent mitochondrial DNA lineages of the brown bear (Ursus arctos) in Scandinavia. Conservation Biology, 9, 1255-1261.

Tajima F (1983) Evolutionary relationships of DNA sequences in finite populations. Genetics, 105, 437-460.

Tajima F (1993) Simple method for testing the molecular evolutionary clock hypothesis. Genetics, 135, 599-607.

Templeton AR (1998) Nested clade analyses of phylogeographic data: testing hypothesis about gene flow and population history. Molecular Ecology, 7, 381-397.

Templeton AR, Crandall KA, Sing CF (1992) A cladistic analysis of phenotypic associations with haplotypes inferred from restriction endonuclease mapping and DNA sequence data. III. Cladogram estimation. Genetics, 132, 619-633.

Templeton AR, Routman E, Phillips CA (1995) Separating population structure from population history: a cladistic analysis of the geographical distribution of mitochondrial DNA haplotypes in the tiger salamander, Ambystoma tigrinum. Genetics, 140, 619-633.

Templeton AR, Sing CF (1993) A cladistic analysis of phenotypic associations with haplotypes inferred from restriction endonuclease mapping. IV. Nested analyses with cladogram uncertainty and recombination. Genetics, 134, 659-669.

Tsuda K, Kikkawa Y, Yonekawa H, Tanable Y (1997) Extensive interbreeding occurred among multiple matriarchal ancestors during the domestication of dogs: evidence from inter- and intraspecies polymorphisms in the D-loop region of mitochondrial DNA between dogs and wolves. Genes and Genetic Systems, 72, 229-238.

Vilà C (1993) Aspectos morfológicos y ecológicos del lobo ibérico Canis lupus L. PhD Thesis, University of Barcelona.

Vilà C, Savolainen P, Maldonado JE et al. (1997) Multiple and ancient origins of the domestic dog. Science, 276, 1687-1689. 
Voigt DR, Berg WE (1987) Coyote. In: (eds Nowak M, Baker JA, Obbard ME, Malloch B) Wild Furbearer Management and Conservation in North America, pp. 345-356. Ministry of Natural Resources, Ontario.

Waits LP, Talbot SL, Ward RH, Shields GF (1998) Mitochondrial DNA phylogeography of the North American brown bear and implications for conservation. Conservation Biology, 12, 408417.

Wayne RK, Jenks SM (1991) Mitochondrial DNA analysis implying extensive hybridization of the endangered red wolf Canis rufus. Nature, 351, 565-568.

Wayne RK, Lehman N, Allard NW, Honeycutt RL (1992) Mitochondrial DNA variability of the gray wolf: genetic consequences of population decline and habitat fragmentation. Conservation Biology, 6, 559-569.

Whitlock MC, McCauley DE (1999) Indirect measures of gene flow and migration: $F_{\mathrm{ST}} \neq 1 /\left(4 N_{m}+1\right)$. Heredity, 82, 117-125.

Winship PR (1989) An improved method for directly sequencing PCR amplified material using DMSO. Nucleic Acids Research, 17, 1266.

Wooding S, Ward R (1997) Phylogeography and Pleistocene evolution in the North American black bear. Molecular Biology and Evolution, 14, 1096-1105.

Wright S (1951) The genetical structure of populations. Annual Eugenics, 15, 323-354.

Young SP, Goldman EA (1944) The Wolves of North America, Part I. American Wildlife Institute, Washington.

This study has been the main research of Carles Vilà in the Conservation Genetics laboratories of Robert K. Wayne, at the University of California, Los Angeles, and Hans Ellegren, at the University of Uppsala (Sweden). Isabel R. Amorim and Jennifer A. Leonard are PhD students at the University of California, Los Angeles. They assisted in the laboratory analysis and in all phases of this study. David Posadas and Keith A. Crandall are interested in the mechanisms of molecular evolution and participated in the data analyses. Javier Castroviejo and Francisco Petrucci-Fonseca, through the Asociación Amigos de Doñana and Grupo Lobo-Portugal, participated in the collection of samples of Eurasian wolves. 